\title{
Clinical Efficacy of Different Ankle Foot Orthosis Design in Subjects with Foot Drop after Stroke: A Review and Comparison
}

\author{
Rajesh Kumar Mohanty ${ }^{* 1}$, Priyanka Behera ${ }^{2}$, Pabitra Kumar Sahoo ${ }^{3}$, Sakti Prasad Das ${ }^{4}$ \\ ${ }^{1}$ Lecturer (Prosthetics and Orthotics), Post Graduate Department of Prosthetics and Orthotics, \\ ${ }^{2}$ Post Graduate Student, Post Graduate Department of Prosthetics and Orthotics, \\ ${ }^{3}$ Assistant Professor and Head, Department of Physical Medicine and Rehabilitation, \\ ${ }^{4}$ Associate Professor (Ortho) and Director \\ Swami Vivekanand National Institute of Rehabilitation Training and Research, Cuttack, Odisha, India.
}

\begin{abstract}
Ankle foot orthoses (AFOs) are usually used for patients with hemiplegic foot drop after stroke to provide support in walking. While the literature provides important information on the beneficial effect of the AFOs, there is still a need for more data describing the impact of different designs of AFOs on gait of subjects during rehabilitation phase after stroke. The aim of this study was to compare the clinical efficacy of two designs of AFOs (Solid and Hinged) on specific gait parameters, kinematics and kinetics during gait by subjects with hemiplegic foot drop after stroke. Thirty subjects with hemiplegic foot drop after stroke participated in this study. Comparison of gait pattern was performed in barefoot, solid and hinged AFO walking conditions. Temporal-spatial, kinematic and kinetic data were collected using force platform (version BTS P-6000, Italy) and six high definition optoelectronic cameras with reflective markers (BTS SMART-DX 6000, Italy) in gait and motion analysis lab. Though subjects walked faster, with a higher cadence and step lengths, when using solid AFO as compared to hinged AFO, the difference was non-significant $(P>0.05)$. Significant difference was observed between gait parameters, kinematics and kinetics of either ankle foot orthosiss compared to barefoot $(\mathrm{P}<0.05)$. Significant difference was observed between two AFOs in mean increase in dorsiflexion at initial contact, peak ankle dorsiflexion during stance, ankle power at push off and peak vertical ground reaction. These findings suggest that, compared to barefoot an AFO yields better gait and thus more effectively manage footdrop, however difference between uses of its variants has almost no impact. Further research to explore the potential utility of these designs of AFOs is indicated.
\end{abstract}

Keywords - Ankle Foot Orthosis; Foot Drop; Gait; Kinematics; Kinetics; Stroke

\section{Introduction}

Stroke is a clinical syndrome characterised by cluster of signs and symptoms due to occlusion of artery supplying a particular region of brain [1]. It is the second leading cause of death and third leading cause of disability globally [2] with increasing prevalence and incidence in India. There has been significant increase in stroke burden in the world over the last two and half decades especially in developing countries like India [3, 4].

Hemiplegia following stroke is characterized by typical posturing with flexor tone predominating in upper extremity and extensor tone in lower extremity [5]. The hemiplegic subjects walk with circumduction gait due to weakness of distal muscles (foot drop) and extensor hypertonia in lower limb [6]. Foot drop is the most common gait abnormality in hemiplegic stroke and is manifested by an inability to actively dorsiflex foot during swing phase (Fig.1). This leads to compensatory movement patterns, slowed gait velocity, limited functional mobility, and increased risk of falls [7, 8, 9]. Active rehabilitation comprising of neurodevelopmental techniques, muscle strengthening, treadmill training, intensive mobility exercises and bracing have been shown to improve the speed and efficiency of walking in patients with hemiplegic stroke [10]. One method often employed to treat foot drop is the use of an ankle foot orthosis (AFO). AFOs have been shown to provide many benefits for improving hemiparetic gait, including increased gait velocity [11], a more symmetrical gait pattern, improved foot clearance during swing [12, 13, 14], and decreased energy expenditure [9].

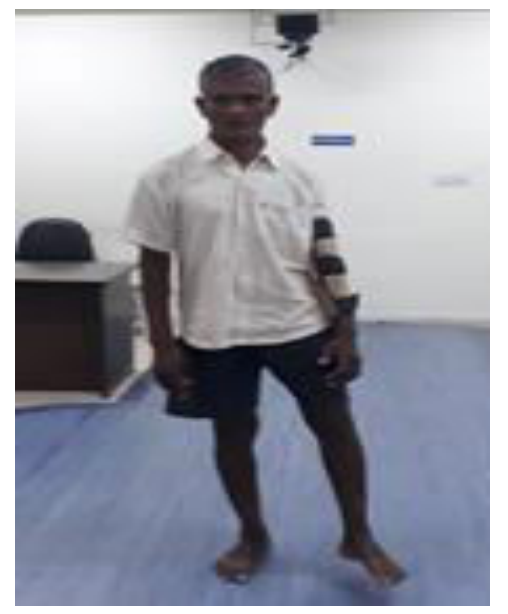

Fig. 1: Hemiplegic Foot drop (Left) with compensatory movements 
Although the use of AFOs in the rehabilitation of stroke patients is common, a variety of different types of AFOs can be used and few studies have looked at their potentially distinct effects on gait [15]. Many studies have evaluated the effects of AFO in stroke subjects (AFO vs. Barefoot). Some authors did comparisons of different types of AFOs with the footwear or barefoot walking but there is still a need of further study.

The hypothesis was that joint kinematics, kinetics and temporal-spatial gait parameters would all be improved when walking with AFOs which either blocked sagittal plane ankle motion, or only allowed ankle dorsi flexion, when compared to a barefoot condition.

\section{Literature Survey}

A systematic literature review was conducted to justify the need of the study. Moreover the technological and clinical aspects of stroke rehabilitation using AFOs were studied and presented in Table1.

Table 1: Literature Review

\begin{tabular}{|c|c|c|c|c|c|}
\hline Study & Type of AFO & $\begin{array}{l}\text { Subjects } \\
(\mathbf{N})\end{array}$ & Outcome Measure & Parameters & Findings \\
\hline $\begin{array}{l}\text { Sankaranarayan } \\
\text { et al. (2016) }\end{array}$ & SAFO & 21 & $\begin{array}{l}\text { 6-minute walk test, } 10 \text { - } \\
\text { meter walk test, FIM }\end{array}$ & $\begin{array}{l}\text { Distance Covered, } \\
\text { Gait Speed }\end{array}$ & $\begin{array}{l}\text { Significant improvement in gait } \\
\text { parameters in only one-third } \\
\text { subjects }\end{array}$ \\
\hline $\begin{array}{l}\text { Andrea Pavlik } \\
(2008)\end{array}$ & $\begin{array}{l}\text { SAFO and } \\
\text { HAFO }\end{array}$ & 4 & $\begin{array}{l}\text { 10-m paper walkway, } \\
\text { TUG test }\end{array}$ & $\begin{array}{l}\text { Gait Speed, } \\
\text { Step length, } \\
\text { Stride length }\end{array}$ & $\begin{array}{l}\text { Significant improvement in } \\
\text { walking speed, step and stride } \\
\text { lengths }\end{array}$ \\
\hline $\begin{array}{l}\text { Farmani et al. } \\
(2016)^{[18]}\end{array}$ & $\begin{array}{l}\text { SAFO with } \\
\text { rocker bar }\end{array}$ & 15 & $\begin{array}{l}\text { 10-m paper walkway, } \\
\text { TUG test }\end{array}$ & Gait Speed & $\begin{array}{l}\text { Higher gait speed and less } \\
\text { time in TUG }(\mathrm{P}<0.05)\end{array}$ \\
\hline $\begin{array}{l}\text { Bulley et al. } \\
(2011)^{[19]}\end{array}$ & $\begin{array}{l}\text { SAFO, PLS- } \\
\text { AFO and FES }\end{array}$ & 9 & $\begin{array}{l}\text { Semi-structured } \\
\text { interviews exploring } \\
\text { individual experiences }\end{array}$ & & $\begin{array}{l}\text { Positive and negative experiences } \\
\text { of both FES and AFO }\end{array}$ \\
\hline $\begin{array}{l}\text { Kluding et al. } \\
(2013)^{[20]}\end{array}$ & $\begin{array}{l}\text { SAFO, HAFO } \\
\text { and FES }\end{array}$ & 197 & $\begin{array}{l}\text { 6-minute walk test, 10- } \\
\text { meter walk test, TUG } \\
\text { test, Balance Test }\end{array}$ & $\begin{array}{l}\text { Gait Speed, } \\
\text { Other functional } \\
\text { outcomes }\end{array}$ & $\begin{array}{l}\text { Either FES or } \text { AFO yielded } \\
\text { clinically } \\
\text { significant }\end{array}$ \\
\hline $\begin{array}{l}\text { Sheffler et al. } \\
(2012)^{[21]}\end{array}$ & $\begin{array}{l}\text { HAFO and } \\
\text { FES }\end{array}$ & 12 & $\begin{array}{l}\text { Spatiotemporal, } \\
\text { kinematic, and kinetic } \\
\text { parameters through } \\
\text { Gait Analysis }\end{array}$ & $\begin{array}{l}\text { Stride length, } \\
\text { Cadence, } \\
\text { Gait Speed, Peak } \\
\text { hip, knee and Ankle } \\
\text { Power generation }\end{array}$ & $\begin{array}{l}\text { Stride length was improved with } \\
\text { both while gait speed improved } \\
\text { with FES, Dorsiflexion status } \\
\text { interaction effect favored the } \\
\text { AFO. }\end{array}$ \\
\hline Ring et al. (2009) & $\begin{array}{l}\text { Standard } \\
\text { AFO Vs. } \\
\text { Neuroprosthe } \\
\text { sis }\end{array}$ & 15 & $\begin{array}{l}\text { 6-minute walk while } \\
\text { wearing force- } \\
\text { sensitive insoles }\end{array}$ & $\begin{array}{l}\text { Gait Speed, } \\
\text { Stride Time, } \\
\text { Swing asymmetry }\end{array}$ & $\begin{array}{l}\text { No significant difference in gait } \\
\text { speed. Stride time, gait symmetry } \\
\text { index improved in both. }\end{array}$ \\
\hline $\begin{array}{l}\text { Nolan et al. } \\
(2010)\end{array}$ & $\begin{array}{l}\text { Dynamic } \\
\text { AFO }\end{array}$ & 1 & $\begin{array}{l}\text { Spatiotemporal and } \\
\text { Kinematic parameters } \\
\text { through gait analysis }\end{array}$ & $\begin{array}{l}\text { Gait speed, } \\
\text { Cadence, Step } \\
\text { length, Stride } \\
\text { length, Step width }\end{array}$ & $\begin{array}{l}\text { Dynamic AFO improved } \\
\text { temporal-spatial parameters and } \\
\text { gait velocity. }\end{array}$ \\
\hline $\begin{array}{l}\text { Tyson \& } \\
\text { Thornton (2001) } \\
\text { [24] }\end{array}$ & HAFO & 25 & $\begin{array}{l}\text { Paper Walk way, } \\
\text { Face-to-face } \\
\text { questionnaire }\end{array}$ & $\begin{array}{l}\text { Stride length, Step } \\
\text { length, Symmetry, } \\
\text { Cadence and Speed }\end{array}$ & $\begin{array}{l}\text { HAFO improved functional } \\
\text { mobility, stride length, cadence } \\
\text { and velocity, but not step length } \\
\text { or symmetry. }\end{array}$ \\
\hline $\begin{array}{l}\text { Rao et al. (2008) } \\
\text { [25] }\end{array}$ & $\begin{array}{l}\text { AFO (Type } \\
\text { not } \\
\text { mentioned) }\end{array}$ & 40 & GAITRite system & $\begin{array}{l}\text { Gait Speed, } \\
\text { Cadence, Step, and } \\
\text { stride length }\end{array}$ & $\begin{array}{l}\text { AFO improves gait velocity, } \\
\text { cadence, step, and stride length }\end{array}$ \\
\hline $\begin{array}{l}\text { Hwang et al. } \\
(2012)^{[26]}\end{array}$ & Dual AFO & 15 & GAITRite system & $\begin{array}{l}\text { Step time, Swing } \\
\text { time, Single support } \\
\text { time, } \\
\text { Speed, Stride } \\
\text { Length }\end{array}$ & 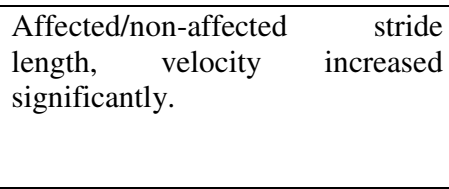 \\
\hline $\begin{array}{l}\text { Shin et al. (2017) } \\
\text { [27] }\end{array}$ & $\begin{array}{l}\text { Standard } \\
\text { AFO Vs. New } \\
\text { multi joint } \\
\text { AFO }\end{array}$ & 15 & $\begin{array}{l}\text { 10-meter walk test, } \\
\text { functional reaching } \\
\text { test and TUG test }\end{array}$ & & $\begin{array}{l}\text { Significant differences in the } \\
\text { orthosis using posterior joint-stop } \\
\text { function. }\end{array}$ \\
\hline $\begin{array}{l}\text { Dogan et al. } \\
(2010)^{[28]}\end{array}$ & HAFO & 51 & $\begin{array}{l}\text { Ashburn walking and } \\
\text { stair test, TUG test, the }\end{array}$ & $\begin{array}{l}\text { Walking Time, } \\
\text { Stair climbing time, }\end{array}$ & $\begin{array}{l}\text { Improvements in gait speed, } \\
\text { balance and mobility with AFO }\end{array}$ \\
\hline
\end{tabular}




\begin{tabular}{|c|c|c|c|c|c|}
\hline & & & $\begin{array}{l}\text { Berg Balance Scale } \\
\text { and the mobility } \\
\text { subscale of the stroke } \\
\text { rehab. }\end{array}$ & $\begin{array}{l}\text { Berg Balance score, } \\
\text { Gait speed }\end{array}$ & $\begin{array}{l}\text { use. No statistically significant } \\
\text { difference between the durations } \\
\text { of stair climbing with or without } \\
\text { AFO }\end{array}$ \\
\hline $\begin{array}{l}\text { Zollo et al. (2015) } \\
\text { [29] }\end{array}$ & $\begin{array}{l}\text { SAFO Vs. } \\
\text { Dynamic } \\
\text { AFO }\end{array}$ & 10 & $\begin{array}{l}\text { Biomechanical gait } \\
\text { analysis }\end{array}$ & $\begin{array}{l}\text { Spatio-temporal, } \\
\text { kinematic and EMG } \\
\text { feature }\end{array}$ & $\begin{array}{l}\text { No significant differences in } \\
\text { spatio-temporal parameters. } \\
\text { SAFO increased co-contraction of } \\
\text { some muscles involved in the } \\
\text { gait. }\end{array}$ \\
\hline$\underset{[30]}{\text { Rao et al. (2014) }}$ & $\begin{array}{l}\text { Off-the-shelf } \\
\text { carbon AFO } \\
\text { and custom } \\
\text { plastic AFO }\end{array}$ & 30 & $\begin{array}{l}\text { GAITRite electronic } \\
\text { walkway }\end{array}$ & $\begin{array}{l}\text { Gait Speed, } \\
\text { Cadence, Stride } \\
\text { length, and step } \\
\text { length }\end{array}$ & $\begin{array}{l}\text { No significant difference in gait } \\
\text { parameters between AFOs but } \\
\text { improved compared to no AFO. }\end{array}$ \\
\hline $\begin{array}{l}\text { Lewallen et al., } \\
\text { (2010) }{ }^{[15]}\end{array}$ & $\begin{array}{l}\text { HAFO, } \\
\text { SAFO, } \\
\text { PLS AFO }\end{array}$ & 13 & GAITRite system & $\begin{array}{l}\text { Step length, Single } \\
\text { support time, and } \\
\text { speed }\end{array}$ & $\begin{array}{l}\text { Compromised gait with SAFO } \\
\text { gait for speed, step length, and } \\
\text { single support time. }\end{array}$ \\
\hline $\begin{array}{l}\text { Gok et al. (2003) } \\
\text { [13] }\end{array}$ & $\begin{array}{l}\text { Seattle-type } \\
\text { polypropylene } \\
\text { AFO and } \\
\text { metallic AFO }\end{array}$ & 12 & $\begin{array}{l}\text { Vicon } 370 \text { Motion } \\
\text { Analysis System }\end{array}$ & $\begin{array}{l}\text { Spatio-temporal, } \\
\text { kinematic and } \\
\text { kinetic parameters }\end{array}$ & $\begin{array}{l}\text { Both orthoses had similar positive } \\
\text { effects No significant difference } \\
\text { between orthosis. }\end{array}$ \\
\hline
\end{tabular}

Abbreviations: FIM; Functional Independence Measure, TUG: timed "Up and Go", SAFO: Solid Ankle Foot Orthosis, HAFO: Hinged Ankle Foot Orthosis, DAFO: Dynamic Ankle Foot Orthosis, PLS AFO: Posterior Leaf Spring Ankle Foot Orthosis.

The following gaps were identified in the literature.

- Though HAFO compared to SAFO had some better effects on gait of stroke subjects, author has suggested for more investigations (Aliyeh Daryabor, 2018) [36]

- There is a need to examine long term effects and costeffectiveness of prescribing variants of AFO in stroke subjects. (Noel Rao et al, 2014) [30]

- Future studies are encouraged for well-designed clinical trials to establish evidence of AFO use on gait in stroke. (Ferreira et al, 2013) [33]

- There is controversy in the results of these studies and conflicting outcome measures.

Therefore the aim of this study was to evaluate and compare the efficacy of two most commonly used plastic AFOs (Solid and Hinged) on the subjects with hemiplegic foot drop due to stroke.

\section{Method}

\subsection{Participants}

Thirty subjects with hemiplegia secondary to stroke were selected from our Institute. Seventeen subjects had right and thirteen subjects had left cerebral lesions. The inclusion criteria are subjects with either sex with first stroke with foot drop, age range- 18 to 60 years, at least 6 weeks post-stroke but not more than 1 year duration, should have an ability to walk and understand and follow command. Subjects having visual impairment, unstable angina, global aphasia, co-ordination problem and using any assistive device during ambulation were excluded. The study protocol was approved by the Institutional Review Board. Signed informed consent was obtained from each of the subjects after explanation of the test procedures and rights of subjects.

\subsection{Ankle Foot Orthosis}

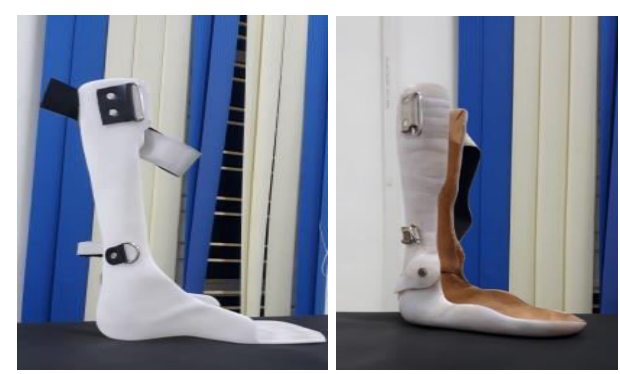

Fig. 2: SAFO (left) and HAFO (right)

The solid AFO (Fig.2) was fabricated with trim lines anterior to the malleoli to prevent ankle dorsiflexion and plantar flexion; the hinged AFO (Fig.2) was fabricated with simple hinge that blocks plantar flexion beyond 90 degrees and allowing free dorsiflexion. The proximal trim lines of both AFOs ended 1 centimetre distal to the neck of the fibula and distal extension is with complete foot plate up to tip of toes. Each AFO had two straps: a two-inch strap at the proximal calf region and a one-inch strap at the instep.

\subsection{Study Tools and Instrumentation}

All temporal-spatial, kinematic and kinetic data were collected using force platform (version BTS P-6000, Italy) and six high definition optoelectronic cameras with reflective markers (BTS SMART-DX 6000, Italy) in gait and motion analysis lab (Fig.3). The sampling rate of force platform is $1000 \mathrm{~Hz}$ and maximum acquisition sampling 
frequency of the optoelectronic cameras is $2000 \mathrm{fps}$. A Helen Hayes model was applied concurrently to track motion of the lower limbs and pelvis through 15 markers placed at different bony landmarks. The obtained data was processed using BTS Smart Analyser and Matlab, including filtering of marker trajectories with a 4th order low-pass Butterworth filter.

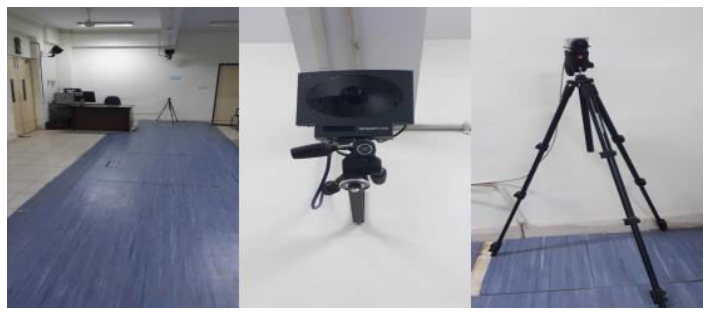

Fig. 3: Gait and Motion Analysis Lab Setup

\subsection{Procedure and Protocol}

After detailed assessment and evaluation, the subjects were randomly divided into two groups. Group A consisting of 15 subjects who used SAFO and 15 subjects using HAFO belong to Group B. Fitting and alignment of AFOs was established by certified Orthotist. Gait training was given to these subjects after fitment of orthosis for few days to gain stability and achieve normal walking. Pertinent demographic and anthropometric data was collected before test. The subjects were psychologically normal with no anxiety, stress, fear etc. Practice trials were performed by each subject until they could consistently and naturally contact both of the force plates. They were taught to walk with their own self-selected walking speed. Each subject walked along walkway with two force plate embedded on floor for each of the two orthotic conditions wearing shoes. Reflective markers were placed on specific anatomic landmarks such as pelvis, hip, knee, ankle and foot following standard protocol. The temporal-spatial (Cadence, Step length, Stride length and Velocity) with kinematic and kinetic data were recorded and compared between two orthotic conditions. To maintain consistency in fit of orthoses and data recording, same investigator was recruited who followed similar protocol and procedure throughout the study.

\subsection{Data analysis}

Each of the four dependent variables such as Cadence, Step length, Stride length and Velocity, were statistically analysed employing two orthotic conditions (SAFO and HAFO) through unpaired t-test. Statistical Package for the Social Sciences (SPSS) v.20 and MS-Excel was used for the statistical analysis. Probability level of $\alpha=0.05$ was accepted as indicative of a statistically significant difference in the individual comparisons.

\section{Results}

A total number of 30 participants having hemiplegic foot drop were selected for the study with the age range from 20-60 years. There were 18 male and 12 female participants. Half of the patients were fitted with SAFO and rest of the patients was fitted with HAFO. No drop outs were there in the study. The demographic data are represented in Table 2.

Table 2: Demographic data

\begin{tabular}{|c|c|c|c|c|c|c|c|}
\hline $\begin{array}{c}\text { Sl. } \\
\text { No }\end{array}$ & Orthosis & $\begin{array}{c}\text { Age } \\
\left(\begin{array}{c}\text { Mean } \\
\pm \text { SD) }\end{array}\right.\end{array}$ & Sex & $\begin{array}{c}\text { No } \\
(\mathbf{N})\end{array}$ & $\begin{array}{c}\text { Weight } \\
(\mathbf{k g})\end{array}$ & $\begin{array}{c}\text { Height } \\
(\mathbf{c m})\end{array}$ & $\begin{array}{c}\text { Mean } \\
\text { time } \\
\text { since } \\
\text { Stroke }\end{array}$ \\
\hline 1 & SAFO & $\begin{array}{c}46.33 \pm \\
9.59\end{array}$ & $\begin{array}{c}\mathrm{M}=10, \\
\mathrm{~F}=5\end{array}$ & 15 & 65.37 & 174.5 & $\begin{array}{c}125 \\
\text { days }\end{array}$ \\
\hline 2 & HAFO & $\begin{array}{c}47.13 \pm \\
7.53\end{array}$ & $\begin{array}{c}\mathrm{M}=8, \\
\mathrm{~F}=7\end{array}$ & 15 & 68.48 & 176.3 & $\begin{array}{c}137 \\
\text { days }\end{array}$ \\
\hline
\end{tabular}

The mean of step length, cadence and velocity in SAFO was found to be slightly higher than HAFO for our subjects with hemiplegic foot drop. However, none of the parameter showed any statistical significant difference between SAFO and HAFO ( $p>0.05)$. The results of spatio-temporal gait parameters are presented in Table 3 .

Table 3: Comparison of gait parameters

\begin{tabular}{|c|c|c|c|c|c|c|}
\hline Parameter & $\begin{array}{c}\text { Barefoot } \\
\text { (A) }\end{array}$ & $\begin{array}{c}\text { SAFO } \\
\text { (B) }\end{array}$ & $\begin{array}{c}\text { HAFO } \\
\text { (C) }\end{array}$ & $\begin{array}{c}\text { P value } \\
\text { (A-B) }\end{array}$ & $\begin{array}{c}P \\
\text { value } \\
\text { (A-C) }\end{array}$ & $\begin{array}{c}\mathbf{P} \\
\text { value } \\
\text { (B-C) }\end{array}$ \\
\hline $\begin{array}{l}\text { Step length } \\
\text { (m) }\end{array}$ & $\begin{array}{c}0.24 \pm \\
0.05\end{array}$ & $\begin{array}{c}0.34 \pm \\
0.08\end{array}$ & $\begin{array}{c}0.26 \pm \\
0.08\end{array}$ & 0.02 & 0.04 & 0.26 \\
\hline $\begin{array}{c}\text { Stride } \\
\text { length }(\mathrm{m})\end{array}$ & $\begin{array}{c}0.52 \pm \\
0.19\end{array}$ & $\begin{array}{c}0.59 \pm \\
0.24\end{array}$ & $\begin{array}{c}0.60 \pm \\
0.22\end{array}$ & 0.007 & 0.008 & 0.97 \\
\hline $\begin{array}{c}\text { Cadence } \\
\text { (steps } / \mathrm{min})\end{array}$ & $\begin{array}{c}58.17 \pm \\
18.45 \\
\end{array}$ & $\begin{array}{c}61.72 \pm \\
20.29 \\
\end{array}$ & $\begin{array}{c}61.07 \pm \\
11.44 \\
\end{array}$ & 0.003 & 0.007 & 0.96 \\
\hline $\begin{array}{c}\text { Velocity } \\
(\mathrm{m} / \mathrm{s})\end{array}$ & $\begin{array}{c}0.27 \pm \\
0.15\end{array}$ & $\begin{array}{c}0.35 \pm \\
0.23\end{array}$ & $\begin{array}{l}0.3 \pm \\
0.18\end{array}$ & 0.03 & 0.04 & 0.77 \\
\hline
\end{tabular}

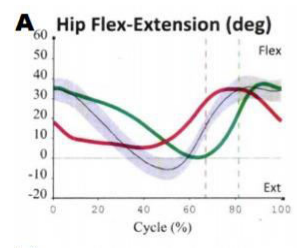

B
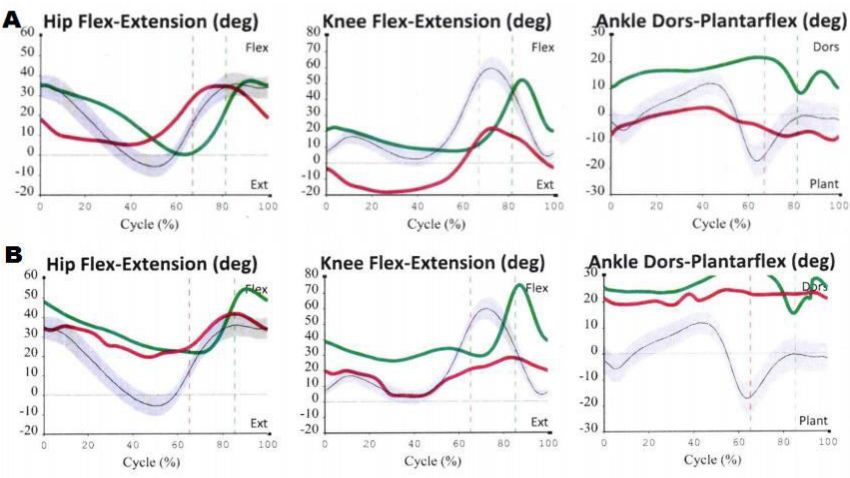

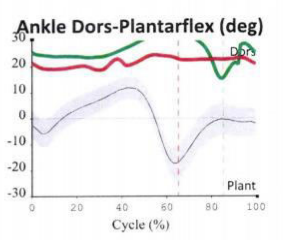

Fig.4: Kinematics of Hip, Knee and Ankle joints, A: Hinged AFO and B: Solid AFO (Red line indicates affected side and green line for normal side) 


\section{A Ground Reaction Force}

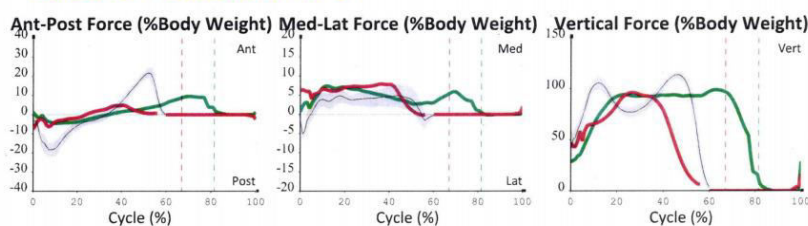

B Ground Reaction Force

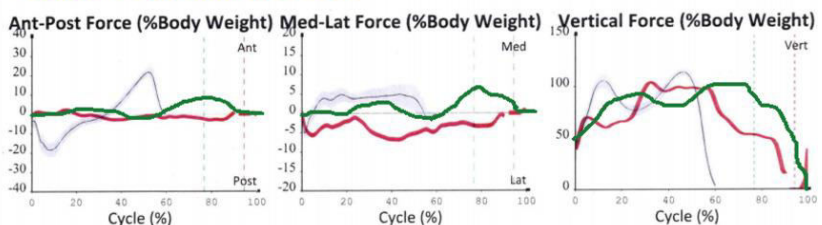

Fig.5: Kinetics (Ground Reaction force) comparison,

A: Hinged AFO and B: Solid AFO (Red line indicates affected side and green line for normal side)

\section{Discussions}

The aim of this study was to compare the clinical efficacy of AFOs (Solid and Hinged) on specific gait parameters, kinematics and kinetics during gait by subjects with hemiplegic foot drop after stroke. It has been reported that the walking speed which is reduced in stroke [31] can be improved with AFO [11]. The use of AFO has beneficial effects in terms of improving functional mobility, quality of gait and decreasing the rate of falls in these subjects $[32,33]$. Thus stroke individuals provided with an AFO improved gait parameters such as cadence, stride length, and gait velocity [13, 34]. Luiz et al [33] aimed to analyse the effect of an AFO on gait variables (velocity and cadence) of stroke patients. While results suggest improvement in gait velocity with AFO, its impact on cadence remains inconclusive. They suggested for further well-designed randomized, controlled, clinical trials to establish better scientific evidence for the effects of AFO usage on gait variables of stroke patients. The literature support on the use of different types of AFO to improve ambulation of stroke individuals is limited.

\subsection{Temporal-spatial gait parameters}

In this study comparison between two most common variants of AFO was performed to check the clinical efficacy in stroke subjects. AFO use considerably improves gait velocity, cadence, step, and stride length of individuals with hemiplegia due to stroke. The results of the current study demonstrated that the use of solid AFO $(0.34 \pm 0.08)$ resulted in slight increase step length compared to HAFO $(0.26 \pm 0.08)$, however they did not show any statistical difference $(p>0.05)$. Stride length, cadence and velocity of both orthotic conditions were almost similar and statistically non-significant. These results are similar to those found by Lewallen et al. [15] where no significant difference among gait parameters was found. The study of
Hesse et al. [35] found that subjects wearing a solid AFO showed improved gait when compared to barefoot and shoes-only conditions.

A study by Daryabor et al [36] showed a direct comparison of solid and hinged AFO. He found that all types of AFOs had positive effects on ankle kinematic in the first rocker and swing phases, but not on knee kinematics in the swing phase, hip kinematics or the third rocker function. The authors found that the articulated passive AFO compared with the non-articulated passive AFO had better effects on some aspects of the gait of patients with hemiplegia following stroke and suggested that more investigations are needed in this regard though. Zollo et al [29] did the biomechanical gait analysis on hemiparetic subjects with foot drop syndrome under 3 conditions with randomized sequences: 1) without AFO; 2) wearing a solid AFO; 3) wearing a dynamic AFO.

Significant changes in spatio-temporal, kinematic and electromyographic features of gait were investigated. The outcome of gait analysis shows that there are no significant differences among the solid and the dynamic AFO on the spatio-temporal parameters. Both SAFO and HAFO reduced range of the ankle motions compared to barefoot. They also reduced the asymmetry between the paretic and the contralateral limb in terms of ankle angle at initial contact and hip flexion. The solid AFO generally led to an increase of the co-contraction of the couples of muscles involved in the gait. This indicates that AFOs can limit foot-drop and improve balance in stroke population. Main difference between AFOs was probably related to muscular activity. Noel Rao et al [30] compared the effects of two types of AFO on gait of patients with stroke and evaluated their preference in using each AFO type design. Thirty individuals with acute hemi paretic CVA were tested without an AFO, with an off-the-shelf carbon AFO (C$\mathrm{AFO}$ ), and with a custom plastic AFO (P-AFO) in random order at the time of initial orthotic fitting. Both types of AFO significantly improved gait velocity, cadence, step length, and stride length in patients with acute stroke.

\subsection{Kinematics}

Ankle kinematics demonstrated an increase in dorsiflexion at initial foot contact and increase in peak ankle dorsiflexion during stance and swing phase with either AFO. An increase in peak dorsiflexion in swing phase and increased peak dorsiflexion at toe-off was observed. These results were similar to studies conducted by earlier researchers [37, 38, 39, 40]. In knee kinematics, an increase in knee flexion at initial response and an increase in peak knee flexion at loading response with an AFO were observed. However, there is no effect on peak knee flexion in swing phase. The preference results are similar to those found by earlier researchers [38]. 
Few studies have evaluated the impact of an AFO on hip kinematics. In terms of peak hip flexion at initial contact, AFO has found no effect which was reiterated when the effect of an AFO on peak hip extension during stance phase was examined. Significant differences were observed for ankle kinematics while knee and hip motions did not show any significant statistics while comparing SAFO and HAFO (Fig.4).

\subsection{Kinetics}

The peak of vertical component of ground reaction force reached maximum in SAFO (100\% body weight) compared to $90 \%$ bodyweight in HAFO (Fig.5). There was no significant difference between these two orthosis with respect to medio-lateral component of ground reaction force. A trend towards significance in ankle power at pushoff between SAFO and HAFO in the group as a whole is notable because of a clinical concern that inhibition of ankle movement by an SAFO may enhance weight-bearing stability in hemiparesis but at the cost of loss of ankle power necessary for optimal walking speeds and forward gait progression. Prior studies [21] have found that an AFO decreases ankle power during both treadmill ambulation and stair locomotion. HAFO diminished ankle power to a lesser degree than a SAFO.

A possible explanation for greater ankle power at pushoff of the SAFO relative to the HAFO is that repetitive dorsiflexion restriction with the SAFO during ambulation may facilitate reciprocal strengthening or functioning of the gastro-soleus complex. Two studies [8, 35] involving 35 participants showed an increase in the length of centre of pressure excursion under the affected foot during stance with the ankle-foot orthosis $(\mathrm{P}<0.0001)$. Other trials $[39$, 41, 42] involving 99 participants measured aspects of the kinetics but there were no common parameters that could be pooled. All reported a significantly positive effect with an AFO except Yamamoto et al. [42] who had reported mixed results in only 10 patients.

\section{Conclusion}

An AFO can improve the temporal-spatial gait parameters, ankle and knee kinematics and kinetics of walking in stroke subjects with foot drop. AFO use significantly improves velocity, cadence, step length and stride length in patients with acute and chronic stroke. There was no significant difference in temporal-spatial parameters and kinematics of gait observed between SAFO and HAFO, though significant difference was noticed with respect to kinetics. This outcome should be taken into consideration while prescribing AFOs. Further study is needed to examine the longer-term effects and the costeffectiveness of prescribing different types of AFO for people with stroke.

\section{Acknowledgements}

Author would desire to acknowledge the subjects for their active participation and cooperation throughout the study.

\section{References}

[1] National Collaborating Centre for Chronic Conditions (UK). Stroke: National Clinical Guideline for Diagnosis and Initial Management of Acute Stroke and Transient Ischaemic Attack (TIA). London: Royal College of Physicians (UK); 2008. (NICE Clinical Guidelines, No. 68)

[2] Lozano R, Naghavi M, Foreman $\mathrm{K}$ et al. Global and regional mortality from 235 causes of death for 20 age groups in 1990 and 2010: a systematic analysis for the Global Burden of Disease Study 2010. Lancet. 380; 2012: 2095-2128

[3] Feigin VL, Forouzanfar MH, Krishnamurthi R, et al; Global Burden of Diseases, Injuries, and Risk Factors Study 2010 (GBD 2010) and the GBD Stroke Experts Group. Global and regional burden of stroke during 1990- 2010: findings from the Global Burden of Disease Study 2010. Lancet 383; 2014: 245-254.

[4] Feigin VL, Lawes CM, Bennett DA, Barker-Collo SL, Parag V. Worldwide stroke incidence and early case fatality reported in 56 population-based studies: a systematic review. Lancet Neurol. 8; 2009: 355-369.

[5] Robert Teasell. Musculoskeletal complications of Hemiplegia Following Stroke. Seminars in Arthritis and Rheumatism 20(6); 1991: 385-395

[6] Balaban, B., \& Tok, F. Gait Disturbances in Patients with Stroke. PM\&R, 6(7); 2014: 635-642.

[7] Cheng PT, Chen CL, Wang CM, Hong WH. Leg muscle activation patterns of sit-to-stand movement in stroke patients. Am J Phys Med Rehabil. 83; 2004:10-16.

[8] Fatone S, Gard SA, Malas BS. Effect of ankle-foot orthosis alignment and foot-plate length on the gait of adults with poststroke hemiplegia. Arch Phys Med Rehabil. 90; 2009:810-818.

[9] Franceschini M, Massucci M, Ferrari L, Agosti M, Paroli C. Effects of an ankle-foot orthosis on spatiotemporal parameters and energy cost of hemiparetic gait. Clin Rehabil. 17; 2003: 368-372.

[10] Eng JJ, Tang PF. Gait training strategies to optimize walking ability in people with stroke: a synthesis of the evidence. Expert Rev Neurother.7(10); $2007:$ 1417-1436.

[11] Wang RY, Lin PY, Lee CC, Yang YR. Gait and balance performance improvements attributable to ankle-foot orthosis in subjects with hemiparesis. Am J Phys Med Rehabil 86(7); 2007: 556-562.

[12] Caillet F, Mertens P, Rabaséda S, Boisson D. Three dimensional gait analysis and controlling spastic foot on stroke patients. Ann Readapt Med Phys 46(3); 2003: :119-131.

[13] Gök H, Küçükdeveci A, Altinkaynak H, et al. Effects of ankle-foot orthoses on hemiparetic gait. Clin Rehabil. 17(2); 2003: 137-139.

[14] Rao N, Chaudhuri G, Hasso D, et al. Gait assessment during the initial fitting of an ankle foot orthosis in individuals with stroke. Disabil Rehabil Assist Technol 3(4); 2008: 201-207.

[15] Lewallen, J., Miedaner, J., Amyx, S., \& Sherman, J. Effect of Three Styles of Custom Ankle Foot Orthoses on the Gait of Stroke Patients While Walking on Level and Inclined Surfaces. JPO Journal of Prosthetics and Orthotics, 22(2); 2010: 78-83. 
[16] Sankaranarayan H, Gupta A, Khanna M, Taly AB, Thennarasu K. Role of ankle foot orthosis in improving locomotion and functional recovery in patients with stroke: A prospective rehabilitation study. $\mathrm{J}$ Neurosci Rural Pract. 7(4); 2016: 544-549.

[17] Pavlik, A. J. The Effect of Long-Term Ankle-Foot Orthosis Use on Gait in the Poststroke Population. JPO Journal of Prosthetics and Orthotics, 20(2); 2004: 49-52.

[18] Farmani F, Mohseni-Bandpei MA, Bahramizadeh M, Aminian Gh, Nikoo MR, Sadeghi-Goghari M. Effectof rocker bar ankle foot orthosis on functional mobility in post-stroke hemiplegic patients: Timed up and go and gait speed assessments. Iranian Rehabilitation Journal. 14(1); $2016: 31-34$.

[19] Bulley, C., Shiels, J., Wilkie, K., \& Salisbury, L. User experiences, preferences and choices relating to functional electrical stimulation and ankle foot orthoses for foot-drop after stroke. Physiotherapy, 97(3); 2011: 226-233.

[20] Patricia M. Kluding, Kari Dunning, Michael w Dell, Jivan Ginosian, Jody feld. Foot drop stimulation versus Ankle foot orthosis after stroke .Journal of Stroke . 44(6); 2013: 1660-1669

[21] Sheffler, L. R., Bailey, S. N., Wilson, R. D., \& Chae, J. Spatiotemporal, Kinematic, and Kinetic Effects of a Peroneal Nerve Stimulator Versus an Ankle Foot Orthosis in Hemiparetic Gait. Neurorehabilitation and Neural Repair, 27(5); 2012: 403-410.

[22] Ring H, Treger I, Gruendlinger L, Hausdorff JM. Neuroprosthesis for footdrop compared with an ankle-foot orthosis: effects on postural control during walking. J Stroke Cerebrovasc Dis. 18(1); 2009: 41-47

[23] Karen J. Nolan, Krupa K. Savaliaa, Mathew Yarossia and Elie P. Elovic. Evaluation of a dynamic ankle foot orthosis in hemiplegic gait: A case report. NeuroRehabilitation. 27; 2010: 343-35

[24] Tyson, S. F., \& Thornton, H. A. The effect of a hinged ankle foot orthosis on hemiplegic gait: objective measures and users' opinions. Clinical Rehabilitation, 15(1); 2001: 53-58.

[25] Rao, N., Chaudhuri, G., Hasso, D., D’Souza, K., Wening, J., Carlson, C., \& Aruin, A. S. Gait assessment during the initial fitting of an ankle foot orthosis in individuals with stroke. Disability and Rehabilitation: Assistive Technology, 3(4); 2008: 201-207.

[26] Young-In Hwanga, Duk-Hyun Anb and Won-Gyu Yoo. Effects of the Dual AFO on gait parameters in stroke patients. NeuroRehabilitation 31; 2012: 387-393.

[27] Shin YJ, Lee DH, Kim MK. The effect of newly designed multi joint ankle foot orthosis on the gait and dynamic balance of stroke patients with foot drop. J Phys Ther Sci. 29(11); 2017:1899-1902.

[28] Doğan, Asuman \& Mengüllüoğlu, Münire \& Özgirgin, Neşe. Evaluation of the effect of ankle-foot orthosis use on balance and mobility in hemiparetic stroke patients. Disability and rehabilitation. 33; 2010: 1433-9.

[29] Zollo L, Zaccheddu N, Ciancio AL, Morrone M, Bravi M, Santacaterina $\mathrm{F}$, et al.Comparative analysis and quantitative evaluation of ankle-foot orthoses for foot drop in chronic hemiparetic patients. Eur J Phys Rehabil Med 51(2); 2015: 185-96.
[30] Rao N, Wening J, Hasso D, Gnanapragasam G, Perera P, Srigiriraju $\mathrm{P}$, Aruin AS. The effects of two different ankle-foot orthoses on gait of patients with acute hemiparetic cerebrovascular accident. Rehabil Res Pract. 2014; 2014:301469.

[31] H. S. Jorgensen, H. Nakayama, H. O. Raaschou, J. Vive-Larsen, M. Stoier, and T. S. Olsen, "Outcome and time course of recovery in stroke, part II: time course of recovery: the Copenhagen Stroke Study," Archives of Physical Medicine and Rehabilitation, 76(5); 1995: 406-412.

[32] E. Cakar, O. Durmus, L. Tekin, U. Dincer, and M. Z. Kiralp, "The ankle-foot orthosis improves balance and reduces fall risk of chronic spastic hemiparetic patients," European Journal of Physical and Rehabilitation Medicine. 46(3); 2010: 363-368.

[33] L. A. Ferreira, H. P. Neto, L. A. Grecco et al., "Effect of ankle-foot orthosis on gait velocity and cadence of stroke patients: a systematic review," Journal of Physical Therapy Science. 25(11); 2013: 1503 1508.

[34] H. Abe, A. Michimata, K. Sugawara, N. Sugaya, and S.-I. Izumi, "Improving gait stability in stroke hemiplegic patients with a plastic ankle-foot orthosis," Tohoku Journal of Experimental Medicine. 218(3); 2009: 193-199.

[35] Hesse S, Luecke D, Jahnke M, Mauritz KH. Gait function in spastic hemiparetic patients walking barefoot, with firm shoes, and with ankle-foot orthosis. Int J Rehabil Res. 19; 1996: 133-141.

[36] Aliyeh Daryabor, Mokhtar Arazpour. Effect of different design of AFO on gait in patients with stroke;a systematic review. Gait and posture . 62; 2018: 268-279

[37] Burdett R, Borello-France D, Blatchly C, Potter C. Gait comparison of subjects with hemiplegia walking unbraced, with ankle-foot orthosis, and with Air-Stirrup brace. Phys Ther. 68(8); 1988: $1197-$ 203.

[38] Hesse S, Werner C, Matthias K, Stephen K, Berteanu M. Nonvelocity-related effects of a rigid double-stopped ankle-foot orthosis on gait and lower limb muscle activity of hemiparetic subjects with an equinovarus deformity. Stroke. 30(9); 1999: 1855-61.

[39] Fatone S, Hansen A. Effect of ankle-foot orthosis on roll-over shape in adults with hemiplegia. J Rehabil Res Dev. 44(1); 2007: 11-20.

[40] Mulroy SJ, Eberly VJ, Gronely JK, Weiss W \& Newsam CJ. Effect of ankle foot orthosis design on walking after stroke: Impact of ankle plantar flexion contracture. Prosthet Orthot Int. 34(3); 2010: 277-292

[41] Kobayashi T, Leung AKL, Akazawa Y and Hutchins SW. Effect of ankle-foot orthoses on the sagittal plane displacement of the center of mass in patients with stroke hemiplegia: a pilot study. Top Stroke Rehabil 19; 2012: 338-344.

[42] Yamamoto SA, Fuchi MB and Yasui TC. Change of rocker function in the gait of stroke patients using an ankle foot orthosis with an oil damper: Immediate changes and the short-term effects. Prosthet Orthot Int.; 35; 2011: 350-359 